\title{
TRAF4 mediates activation of TGF- $\beta$ signaling and is a biomarker for oncogenesis in breast cancer
}

\author{
ZHOU FangFang ${ }^{1,2^{*}}$, LI Fang ${ }^{1}$, XIE Feng ${ }^{1}$, ZHANG ZhengKui ${ }^{1}$, HUANG HuiZhe ${ }^{3 *} \&$ \\ ZHANG Long ${ }^{1,2 *}$ \\ ${ }^{1}$ Life Sciences Institute, Zhejiang University, Hangzhou 310058, China; \\ ${ }^{2}$ Department of Molecular Cell Biology, Cancer Genomics Centre Netherlands and Centre for Biomedical Genetics, Leiden University \\ Medical Center, Postbus 96002300 RC Leiden. The Netherlands \\ ${ }^{3}$ Faculty of Basic Medical Sciences, Chongqing Medical University, Chongqing 400016, China
}

Received December 19, 2013; accepted February 20, 2014; published online September 22, 2014

\begin{abstract}
The tumor-promoting arm of transforming growth factor beta (TGF- $\beta$ ) receptor signaling contributes to advanced cancer progression and is considered a master regulator of breast cancer metastasis. In mammals, there are six distinct members in the tumor-necrosis factor receptor (TNFR)-associated factor (TRAF) family (TRAF1-TRAF6), with the function of TRAF4 not being extensively studied in the past decade. Although numerous studies have suggested that there is elevated TRAF4 expression in human cancer, it is still unknown in which oncogenic pathway TRAF4 is mainly implicated. This review highlights TGF- $\beta$-induced SMAD-dependent signaling and non-SMAD signaling as the major pathways regulated by TRAF4 involved in breast cancer metastasis.
\end{abstract}

TRAF4, TGF- $\beta$, breast cancer, metastasis

Citation: Zhou FF, Li F, Xie F, Zhang ZK, Huang HZ, Zhang L. TRAF4 mediates activation of TGF- $\beta$ signaling and is a biomarker for oncogenesis in breast cancer. Sci China Life Sci, 2014, 57: 1172-1176, doi: 10.1007/s11427-014-4727-x

Transforming growth factor beta (TGF- $\beta$ ) receptor signaling drives cancer metastasis, and the stability and membrane localization of its receptor is an important determinant in controlling the intensity and duration of TGF- $\beta$ signaling. A genome-wide cDNA screen identified multiple important positive regulators of TGF- $\beta-S M A D$ signaling [1-3]. Among them, a distant tumor-necrosis factor receptor (TNFR)-associated factor (TRAF) family member, TRAF4, is of interest as it could target different substrates to play positive roles in both SMAD-dependent and SMADindependent TGF- $\beta$ signaling. This apparently contributes to tumor cell migration. Importantly, TRAF4 gene copy

*Corresponding author (email: F.Zhou@lumc.nl; devbiology@ cqmu.edu.cn;

L_Zhang@zju.edu.cn) number is increased in multiple cancer types and amplified the most in breast cancer patients. Variations in TRAF4 expression accordingly modulate signaling readout and also TGF- $\beta$ promoted phenotypes such as epithelial to mesenchymal transition (EMT) and tumor cell invasion and metastasis.

In vivo experiments involving established animal metastasis models have verified the critical role that TRAF4 plays, and analyses of human patient samples further confirmed that TRAF4 correlates with poor prognosis. In this short review, we introduce both the background and work in progress on TRAF4-regulated TGF- $\beta$ receptor signaling. We propose a working model of TRAF4 and highlight its critical role in controlling breast cancer metastasis. 


\section{TRAF4, an unusual TRAF family member}

The TRAF family consists of six members. Except for TRAF4, all other TRAFs were identified in a yeast two-hybrid screen using cytoplasmic domains from various members of the TNFR family [4]. Since the original study that identified TRAF1 and TRAF2 as the first members associating with TNFR2, the following work has provided strong evidence that TRAF2, TRAF3, TRAF5 and TRAF6 are all involved in either canonical or alternative nuclear factor- $\kappa \mathrm{B}(\mathrm{NF}-\kappa \mathrm{B})$ activation. (For the distinct role of these TRAFs in NF- $\kappa B$ signaling pathways, we refer the reader to an excellent review [4].)

While later studies verified that TRAF1, TRAF2, TRAF3, TRAF5 and TRAF6 acted as adaptor proteins for various cell surface TNFRs and interleukin-1/Toll-like receptors (IL-1R/TLR) to mediate activation of NF- $\kappa \mathrm{B}$ and activator protein 1 (AP1), it has not yet been demonstrated that TRAF4 functions in a similar manner [4,5]. Although all TRAF proteins share largely the same structure, such as an $\mathrm{N}$-terminal RING finger domain, a middle zinc finger domain (not in TRAF1) and a conserved C-terminal TRAF domain, simplified in a comparison between TRAF4 and TRAF6 (Figure 1), TRAF4 seems to be unique as it is the only member that has seven zinc finger repeats (TRAF2, TRAF3, TRAF5 and TRAF6 contain five zinc finger repeats) [4]. Functionally distinct from other TRAFs that are mainly involved in the immune system [6,7], TRAF4 does not seem to play a role in the immune system as no immunological defects have been identified in mice lacking TRAF4 [8,9].

\section{TRAF4, an amplified gene in breast cancer}

As a RING domain-containing E3 ligase, TRAF4 was originally identified in a differential expression screen using a cDNA library of breast cancer-derived metastatic lymph nodes [10]. Further study showed that TRAF4 overexpression was a common characteristic of human carcinomas [11]. This is likely due to amplification or gain of gene copies in cancer. The TRAF4 gene, which is located in an amplified region of chromosome, is amplified in breast cancer and this is correlated with ERBB2 amplification in breast cancer patients [3,12]. Importantly, analysis of data from the TCGA database showed that TRAF4 gene amplification was also found in many other types of cancer, such as

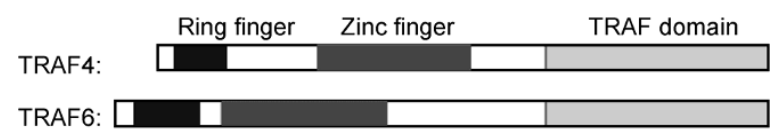

Figure 1 Representative structures of the tumor-necrosis factor receptor (TNFR)-associated factor (TRAF) family member TRAF4 and TRAF6. A RING finger domain in the N-terminal, a zinc finger motif and a carboxy-terminal TRAF domain are shown in different grey scale. bladder urothelial carcinoma and ovarian cancer, suggesting that TRAF4 is oncogenic and its possible role is not limited to breast cancer [3]. The pro-oncogenic role of TRAF4 is linked to the altering of cell mobility since the TRAF4deficient mice showed impaired neural tube closure and tracheal ring disruption, both of which are closely associated with abnormal cell migration $[8,9]$.

\section{TGF- $\beta$, a master regulator of breast cancer metastasis}

Cancer is a complex disease with multiple cellular signaling pathways that are cross-regulated. TGF- $\beta$ signaling is tumor suppressive in the pre-malignant stage but contributes to malignant cancer progression by serving as a strong driving force for cancer metastasis [13,14]. Type II and type I serine/threonine kinase receptors (T $\beta \mathrm{RII}$ and T $\beta \mathrm{RI}$, respectively) mediate TGF- $\beta$ signals. Upon binding of the TGF- $\beta$ ligand, T $\beta$ RII and T $\beta$ RI form a heteromeric receptor complex. Phosphorylation of T $\beta$ RI by T $\beta$ RII on serine and threonine residues in a glycine/serine-rich domain triggers T $\beta$ RI kinase activity. The activated T $\beta$ RI phosphorylates downstream SMAD2/SMAD3 to induce its association with SMAD4, which accumulates in the nucleus and regulates transcription [13-16]. SMAD complex-mediated transcriptional induction of mesenchymal markers and pro-migratory genes provide the TGF- $\beta$ pathway with a potent role in driving EMT and promoting invasion and metastases in advanced cancers $[17,18]$.

Recent discoveries have shown that activation of SMAD-independent pathways by TGF- $\beta$ also contribute to the pro-oncogenic role of TGF- $\beta$ in malignant tumors $[17,19,20]$. In line with this, positive effects from antiTGF- $\beta$ signaling therapies have been shown to reduce breast cancer invasion and metastasis [21-26]. Efficient TGF- $\beta$ pathway inhibitory drugs have been developed and tested in preclinical studies, and some are currently in clinical trials showing expected results [27,28].

\section{TRAF4 targets SMURF2 degradation and mediates SMAD activation by TGF- $\beta$}

The pulse and duration of TGF- $\beta$ signaling is mainly controlled by TGF- $\beta$ receptor activity. While the inhibitory SMAD7-SMURF2 complex targets TGF- $\beta$ receptor for polyubiquitination and inhibits downstream SMAD activation, deubiquitinases, USP4/15, remove ubiquitin chains from T $\beta$ RI, thus stabilizing the TGF- $\beta$ receptor $[2,29,30]$. In a proteomic tandem affinity purification (TAP) screen, SMURF2 was identified as a strong binding partner of TRAF4 [3]. As a substrate, SMURF2 triggered polyubiqui- 
tination and degradation by TRAF4 [3]. Inversely, as a HECT domain-containing E3 ligase, SMURF2 could also initiate polyubiquitin conjugation on TRAF4, resulting in TRAF4 protein degradation via the proteasome [3] (Figure $2 \mathrm{~A})$. These observations raise an interesting question as to when and where these two E3 ligases interact with each other.

In response to TGF- $\beta$ and in a time-dependent but SMAD7-independent manner, TRAF4 was observed to be recruited to the TGF- $\beta$ receptor complex prior to the recruitment of SMURF2 [3]. This indicates that a sequential binding event occurred on the TGF- $\beta$ receptor; in other words, during TGF- $\beta$ signaling, the receptor dictates transient activation (recruitment) of TRAF4 and degradation of SMURF2, eliminating the negative impact of SMURF2 on signaling, at least in the period when signaling is just initiated [31]. Evidence shows that the receptor-TRAF4 association precedes SMURF2 recruitment, and receptor-bound TRAF4 actively ubiquitylates and degrades SMURF2 [3,31]. Biotin could be used to label the TGF- $\beta$ receptor largely on the cell membrane, thus streptavidin beads could allow for the pull-down of the active membrane-located TGF- $\beta$ receptor. It has been noted that TRAF4 action on (eliminating) SMURF2 could positively impact active TRRI levels [3]. Consistently, TRAF4-deficient mouse embryonic fibroblasts appear less responsive to TGF- $\beta$ as a readout of SMAD activation [3]. Therefore, elimination of SMURF2 by TRAF4 apparently contributes to TGF- $\beta$ receptor stability on the plasma membrane.
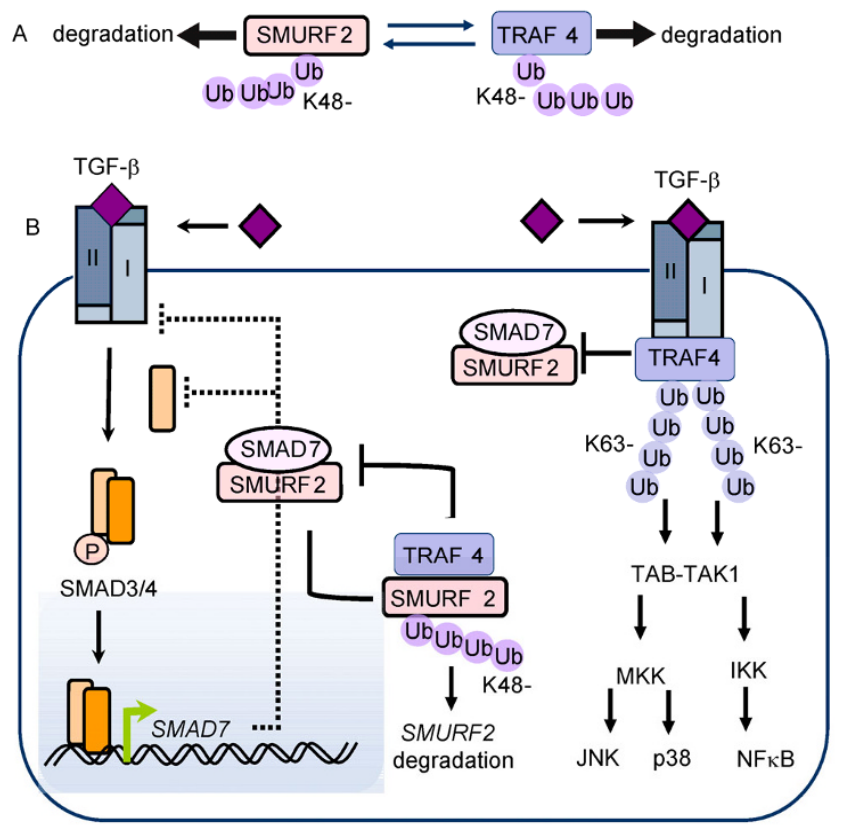

Figure 2 (color online) A, TRAF4 targets SMURF2 and is targeted by SMURF2 for proteasomal degradation. B, TRAF4-involved regulation of transforming growth factor (TGF)- $\beta / S M A D$ (SMA- and MAD-related protein) signaling and SMAD-independent signaling in cancer progression.

\section{TRAF4 stimulates TAK1-mediated activation of non-SMAD TGF- $\beta$ signaling}

In response to TGF- $\beta$ stimulation, T $\beta$ RI-associated TRAF4 protein rapidly undergoes degradation-independent ubiquitination in which the K63-linked polyubiquitin chain is clearly identified [3]. This in turn stimulates TAK1 (and p-TAK1), a ubiquitin-dependent kinase that is also activated by other TRAF family members [32-35]. Similar to the actions of other TRAF members and distinctly in response to the TGF- $\beta$ receptor but not TNFR, K63-polyubiquitination of TRAF4 recruits/activates TAB-TAK1 [3], a protein kinase that stimulates activity of MKK and IKK. These latter two kinases can activate the $\mathrm{p} 38$ kinase/JNK kinase and NFkB pathways for multiple downstream readouts [32] (Figure 2B); consistently, gathered evidence from TRAF4 depleted cells suggests an impaired $\mathrm{p} 38 / \mathrm{NFkB}$ activation by TGF- $\beta$ [3]. Therefore, TRAF4 mediates TAK1-dependent non-SMAD TGF- $\beta$ signaling (Figure 2B).

\section{TRAF4 contributes to breast cancer metastasis}

Influenced by stromal cells, primary tumor cells undergo EMT or use other means to invade the circulation and become circulating tumor cells (CTCs) [36]. CTCs are protected by platelets and further undergo EMT due to TGF- $\beta$ signaling. Tumor-derived factors and exosomes mobilize bone marrow-derived cells to form a pre-metastatic niche to promote the seeding and expansion of metastasis and stromal components at the metastasis niches that enhance tumor survival, stemness and immune evasion [37]. In epithelial-like breast cancer cells, TRAF4 depletion impaired EMT, and in mesenchymal-like cells, TRAF4 depletion led to loss of cell mobility. Consistently, TRAF4-deficient cells exhibited enhanced cell-cell adherence and reduced cell migratory capacity; importantly, in vivo analysis showed a loss of metastasis upon TRAF4 depletion in zebrafish and mice xenograft models that were dependent on TGF- $\beta$ receptor signaling [3]. Additionally, SMURF1-mediated lysine 190 ubiquitination of TRAF4 is thought to target TRAF4 to tight-junctions, where TRAF4 was recently proven to interact with phosphoinositides (PIPs) to increase cell mobility $[38,39]$.

\section{TRAF4 correlates with poor prognosis in breast cancer patients}

In line with the TRAF4 gene amplification and the function of TRAF4 in driving breast cancer metastasis, TRAF4 levels correlated with both SMAD and TAK1 activation and poor prognosis, as observed in over 500 breast cancer pa- 

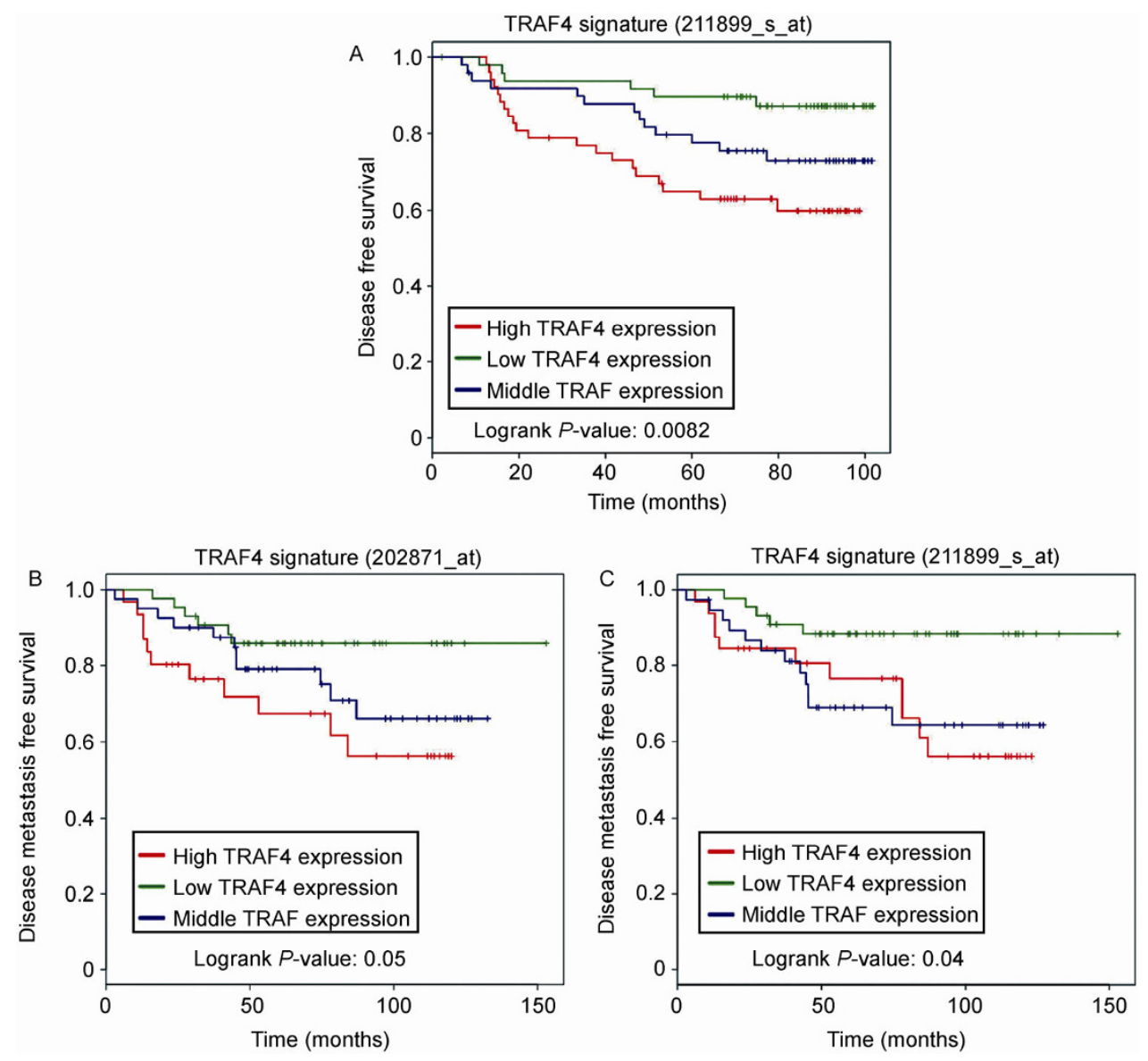

Figure 3 Kaplan-Meier plots of disease-free survival of patients, stratified by expression of TRAF4. Data obtained from the Kaplan-Meier plotter database $[40,41]$. The $P$-value was calculated using a log-rank test.

tients [3]. Analyses have suggested that high TRAF4 expression is an indicator of poor outcome in cancer patients [3]. Furthermore, in a broader analysis where TRAF4 level was examined in further detail, in which patients were stratified into low (33\%), middle (33\%) and high (33\%) expression groups, a clear trend associating TRAF4 level with outcome was clearly observed (Figure 3 ). There was apparently poor disease-free survival for the middle TRAF4 level and an even worse outcome for patients with a high TRAF4 level (Figure 3A). When distant metastasis-free survival was taken into account, a similar statistically significant trend was also apparent when patients were divided into the same TRAF4 expression groups as above (Figure 3B and $3 \mathrm{C})$. Taken together with all the biochemical findings and clinical analyses, the results demonstrate that TRAF4 could be regarded as a biomarker for a subset of breast cancer patients, for which anti-TGF- $\beta$ therapy might be effective.

\section{Conclusion}

As a more distant member of the TRAF family, TRAF4 has not been linked to TNF receptor or Toll-like receptor func- tion. It was recently found to promote signaling of the TGF- $\beta$ family by associating with the TGF- $\beta$ receptor and antagonizing SMURF2 function as an amplified gene in breast cancer. As E3 ligase activity is druggable, both in vitro and in vivo evidence has exposed TFAF4 as a putative biomarker for malignant breast cancer progression and a possible therapeutic target.

The authors declare that they have no conflict of interest.

This work was supported by the Zhejiang University Special Fund for Fundamental Research and the Fundamental Research Funds for the Central Universities (R14C070002) and the Netherlands Organization of Scientific Research grant (MW-NWO 918.66.606), from the Cancer Genomics Centre Netherlands and the Centre for Biomedical Genetics.

1 Zhang L, Huang H, Zhou F, Schimmel J, Pardo CG, Zhang T, Barakat TS, Sheppard KA, Mickanin C, Porter JA, Vertegaal AC, van Dam H, Gribnau J, Lu CX, ten Dijke P. Mol Cell, 2012, 46: 650-661

2 Zhang L, Zhou F, Drabsch Y, Gao R, Snaar-Jagalska BE, Mickanin C, Huang H, Sheppard KA, Porter JA, Lu CX, ten Dijke P. Nat Cell Biol, 2012, 14: 717-726

3 Zhang L, Zhou F, Garcia de Vinuesa A, de Kruijf EM, Mesker WE, Hui L, Drabsch Y, Li Y, Bauer A, Rousseau A, Sheppard KA, Mick- 
anin C, Kuppen PJ, Lu CX, Ten Dijke P. Mol Cell, 2013, 51: $559-572$

4 Signalling pathways of the TNF superfamily: a double-edged sword. Nat Rev Immunol, 2003, 3: 745-756

5 Ha H, Han D, Choi Y. TRAF-mediated TNFR-family signaling. Curr Protoc Immunol, 2009, 87: 11.9D.1-11.9D.19

6 Chung JY, Park YC, Ye H, Wu H. All TRAFs are not created equal: common and distinct molecular mechanisms of TRAF-mediated signal transduction. J Cell Sci, 2002, 115: 679-688

7 Kedinger V, Rio M C. TRAF4, the unique family member. Adv Exp Med Biol, 2007, 597: 60-71

8 Regnier CH, Masson R, Kedinger V, Textoris J, Stoll I, Chenard MP, Dierich A, Tomasetto C, Rio MC. Impaired neural tube closure, axial skeleton malformations, and tracheal ring disruption in TRAF4deficient mice. Proc Natl Acad Sci USA, 2002, 99: 5585-5590

9 Shiels H, Li X, Schumacker PT, Maltepe E, Padrid PA, Sperling A, Thompson CB, Lindsten T. TRAF4 deficiency leads to tracheal malformation with resulting alterations in air flow to the lungs. Am J Pathol, 2000, 157: 679-688

10 Regnier CH, Tomasetto C, Moog-Lutz C, Chenard MP, Wendling C, Basset P, Rio MC. Presence of a new conserved domain in CART1, a novel member of the tumor necrosis factor receptorassociated protein family, which is expressed in breast carcinoma. J Biol Chem, 1995, 270: $25715-25721$

11 Camilleri-Broet S, Cremer I, Marmey B, Comperat E, Viguie F, Audouin J, Rio MC, Fridman WH, Sautes-Fridman C, Regnier CH. TRAF4 overexpression is a common characteristic of human carcinomas. Oncogene, 2007, 26: 142-147

12 Bieche I, Tomasetto C, Regnier CH, Moog-Lutz C, Rio MC, Lidereau R. Two distinct amplified regions at 17q11-q21 involved in human primary breast cancer. Cancer Res, 1996, 56: 3886-3890

13 Moustakas A, Heldin C $\mathrm{H}$. The regulation of TGF $\beta$ signal transduction. Development, 2009, 136: 3699-3714

14 Kang J S, Liu C, Derynck R. New regulatory mechanisms of TGF- $\beta$ receptor function. Trends Cell Biol, 2009, 19: 385-394

15 Ikushima H, Miyazono K. TGF $\beta$ signalling: a complex web in cancer progression. Nat Rev Cancer, 2010, 10: 415-424

16 Massague J. TGF $\beta$ in cancer. Cell, 2008, 134: 215-230

17 Zhang L, Zhou F, ten Dijke P. Signaling interplay between transforming growth factor- $\beta$ receptor and PI3K/AKT pathways in cancer. Trends Biochem Sci, 2013, 38: 612-620

$18 \mathrm{Xu}$ J, Lamouille S, Derynck R. TGF- $\beta$-induced epithelial to mesenchymal transition. Cell Res, 2009, 19: 156-172

19 Zhang Y E. Non-Smad pathways in TGF- $\beta$ signaling. Cell Res, 2009, 19: $128-139$

20 Mu Y, Gudey S K, Landstrom M. Non-Smad signaling pathways. Cell Tissue Res, 2012, 347: 11-20

21 Yang, YA, Dukhanina O, Tang B, Mamura M, Letterio JJ, MacGregor J, Patel SC, Khozin S, Liu ZY, Green J, Anver MR, Merlino G, Wakefield LM. Lifetime exposure to a soluble TGF- $\beta$ antagonist protects mice against metastasis without adverse side effects. J Clin Invest, 2002, 109: 1607-1615

22 Muraoka RS, Dumont N, Ritter CA, Dugger TC, Brantley DM, Chen J, Easterly E, Roebuck LR, Ryan S, Gotwals PJ, Koteliansky V, Arteaga CL. Blockade of TGF- $\beta$ inhibits mammary tumor cell viability, migration, and metastases. J Clin Invest, 2002, 109: 1551-1559

23 Bandyopadhyay A, Lopez-Casillas F, Malik SN, Montiel JL, Mendoza V, Yang J, Sun LZ. Antitumor activity of a recombinant soluble betaglycan in human breast cancer xenograft. Cancer Res, 2002, 62: 4690-4695

24 Hu Z, Zhang Z, Guise T, Seth P. Systemic delivery of an oncolytic adenovirus expressing soluble transforming growth factor- $\beta$ receptor II-Fc fusion protein can inhibit breast cancer bone metastasis in a mouse model. Hum Gene Ther, 2010, 21: 1623-1629

25 Bandyopadhyay A, Agyin JK, Wang L, Tang Y, Lei X, Story BM, Cornell JE, Pollock BH, Mundy GR, Sun LZ. Inhibition of pulmonary and skeletal metastasis by a transforming growth factor- $\beta$ type I receptor kinase inhibitor. Cancer Res, 2006, 66: 6714-6721

26 Korpal M, Yan J, Lu X, Xu S, Lerit DA, Kang Y. Imaging transforming growth factor-beta signaling dynamics and therapeutic response in breast cancer bone metastasis. Nat Med, 2009, 15: 960-966

27 Seoane J. Imaging transforming growth factor $\beta$ signaling dynamics and therapeutic response in breast cancer bone metastasis. Clin Transl Oncol, 2008, 10: 14-19

28 Akhurst R J, Hata A. Targeting the TGF $\beta$ signalling pathway in disease. Nat Rev Drug Discov, 2012, 11: 790-811

29 Kavsak P, Rasmussen RK, Causing CG, Bonni S, Zhu H, Thomsen GH, Wrana JL. Smad7 binds to Smurf2 to form an E3 ubiquitin ligase that targets the TGF $\beta$ receptor for degradation. Mol Cell, 2000, 6: $1365-1375$

30 Eichhorn PJ, Rodon L, Gonzalez-Junca A, Dirac A, Gili M, Martinez-Saez E, Aura C, Barba I, Peg V, Prat A, Cuartas I, Jimenez J, Garcia-Dorado D, Sahuquillo J, Bernards R, Baselga J, Seoane J. USP15 stabilizes TGF- $\beta$ receptor I and promotes oncogenesis through the activation of TGF- $\beta$ signaling in glioblastoma. Nat Med, 2012, 18: 429-435

31 Moustakas A, Heldin C H. Coordination of TGF- $\beta$ signaling by ubiquitylation. Mol Cell, 2013, 51: 555-556

32 Wang C, Deng L, Hong M, Akkaraju GR, Inoue J, Chen ZJ. TAK1 is a ubiquitin-dependent kinase of MKK and IKK. Nature, 2001, 412: 346-351

33 Xia ZP, Sun L, Chen X, Pineda G, Jiang X, Adhikari A, Zeng W, Chen ZJ. Direct activation of protein kinases by unanchored polyubiquitin chains. Nature, 2009, 461: 114-119

34 Sorrentino A, Thakur N, Grimsby S, Marcusson A, von Bulow V, Schuster N, Zhang S, Heldin CH, Landstrom M. The type I TGF- $\beta$ receptor engages TRAF6 to activate TAK1 in a receptor kinase-independent manner. Nat Cell Biol, 2008, 10: 1199-1207

35 Yamashita M, Fatyol K, Jin C, Wang X, Liu Z, Zhang YE. TRAF6 mediates Smad-independent activation of JNK and p38 by TGF- $\beta$. Mol Cell, 2008, 31: 918-924

36 Friedl P, Alexander S. Cancer invasion and the microenvironment: plasticity and reciprocity. Cell, 2011, 147: 992-1009

37 Kang Y, Pantel K. Tumor cell dissemination: emerging biological insights from animal models and cancer patients. Cancer Cell, 2013, 23: 573-581

38 Wang X, Jin C, Tang Y, Tang L Y, Zhang YE. Ubiquitination of tumor necrosis factor receptor-associated factor 4 (TRAF4) by Smad ubiquitination regulatory factor 1 (Smurf1) regulates motility of breast epithelial and cancer cells. J Biol Chem, 2013, 288: 21784-21792

39 Rousseau A, McEwen AG, Poussin-Courmontagne P, Rognan D, Nomine Y, Rio MC, Tomasetto C, Alpy F. TRAF4 is a novel phosphoinositide-binding protein modulating tight junctions and favoring cell migration. PLoS Biol, 2013, 11: e1001726

40 Ur-Rehman S, Gao Q, Mitsopoulos C, Zvelebil M. ROCK: a resource for integrative breast cancer data analysis. Breast Cancer Res Treat, 2013, 139: 907-921

41 Loi S, Haibe-Kains B, Desmedt C, Wirapati P, Lallemand F, Tutt AM, Gillet C, Ellis P, Ryder K, Reid JF, Daidone MG, Pierotti MA, Berns EM, Jansen MP, Foekens JA, Delorenzi M, Bontempi G, Piccart MJ, Sotiriou C. Predicting prognosis using molecular profiling in estrogen receptor-positive breast cancer treated with tamoxifen. BMC Genomics, 2008, 9: 239

Open Access This article is distributed under the terms of the Creative Commons Attribution License which permits any use, distribution, and reproduction in any medium, provided the original author(s) and source are credited. 